\title{
O INQUIETANTE NO ATO DA COMUNICAÇÃO: A RELAÇÃO DE IDENTIDADE E ALTERIDADE A PARTIR DO TWITTER BRITISH LOGIC ${ }^{l}$
}

\author{
The Uncanny in the act of Communication: the relation between identity \\ and otherness on the BritishLogic Twitter
El inquietante en el acto de la Comunicación: la relación de identidad y alteridad a partir del Twitter British Logic

Luis Mauro Sá Martino

Professor do Programa de Pós-Graduação da Faculdade Cásper Líbero (SP) lmsamartino@gmail.com

Ângela Cristina Salgueiro Marques Professora do Programa de Pós-Graduação em Comunicação Social da UFMG angelasalgueiro@gmail.com

\section{Resumo}

Este texto delineia alguns aspectos da relação entre identidade e alteridade a partir da análise das postagens da página britânica BritishLogic (@BritishLogic), na rede social digital Twitter. A partir do conceito de "inquietante", formulado por Freud (2010[1919]), foram analisados os "tweets" entre dezembro de 2015 e maio de 2016 para delinear como a questão do "estranho" é desvelada na descrição atividades triviais do cotidiano. Três elementos ganham destaque no tweet: (a) a trivialidade das ações é retratada como fonte de inquietação cotidiana; (b) a dificuldade de definir e expressar sentimentos nas interações sociais; (c) práticas sociais são problematizadas, reprimidas e deslocadas de sua condição original, em um contínuo estranhamento das próprias atitudes. Esses elementos são discutidos aproximando a ideia de estranhamento e Comunicação.

Palavras-chave: Inquietante. Alteridade. Mídias Digitais.

\begin{abstract}
This text outlines some aspects of the relationship between identity and otherness as it is presented on the British Logic (@BritishLogic) account on Twitter. Grounded on Freud's concept of 'the uncanny', all posts from posts from December 2015 to May 2016 have been analyzed to understand how the posts highlights the 'strangeness' while describing particularly trivial activities of everyday life. Main findings include three major aspects: (a) everyday practices are seen from a distant point of view, as if the most trivial of actions

\footnotetext{
${ }^{1}$ Uma versão anterior deste artigo foi apresentada no IX Simpósio Nacional da ABCiber, realizado na PUC-SP, de 8 a 10 de dezembro de 2016. O trabalho contou com o apoio do CNPq e da Fapemig.
} 
encompasses a great deal of doubt and strangeness; (b) social interactions are portrayed as an endless game of not displaying real feelings; (c) any sort of social awkwardness is immediately repressed in order not to disturb - and not be disturbed by - anyone, but at a cost of inner dissatisfaction.

Key words: The Uncanny. Otherness. Digital Media.

\section{Resumen}

Este texto delinea algunos aspectos de la relación entre identidad y alteridad a partir del análisis de las interacciones delineadas en la página BritishLogic (@BritishLogic), en la red social digital Twitter. A partir del concepto de "inquietante", formulado por Freud (2010 [1919], se analizaron todos los "tweets" entre diciembre de 2015 y mayo de 2016 con el objetivo de analizar cómo la cuestión del "extraño" es desvelada a partir de la descripción de situaciones cotidianas reconocibles y, al mismo tiempo, extrañas cuando se observan en conversaciones políticas ordinarias a las que los interlocutores están acostumbrados. Tres elementos ganan destaque en el tweet: (a) la trivialidad de las acciones es retratada como fuente de inquietud cotidiana; (b) la dificultad de definir y expresar sentimientos en las interacciones sociales; (c) las interacciones comunicacionales son problematizadas, reprimidas y desplazadas de su condición original, en un continuo extrañamiento de las propias actitudes. Estos elementos se discuten aproximando la idea de extrañamiento y comunicación.

Palabras clave: El inquietante. Otredad. Medios Digitales.

\section{INTRODUÇÃO}

A questão do estranhamento, do inquietante e do estrangeiro, em sua relação comunicacional de proximidade e diferença, é um tema presente em vários estudos, mas nem sempre problematizado a partir da abordagem da comunicação com o diferente. Kristeva (1988), em seu livro Étranges a nous mêmes, "Estranhos" ou "Estrangeiros a nós mesmos", indica no título uma proposição que endereça diversos questionamentos e desafios a expectativa de uma lógica linear e integrada nos atos de Comunicação para pensar a diferença. No mesmo sentido, Koltai $(2000 ; 2015)$ ressalta a questão do estranho a partir de seu duplo jogo com a tradução "estrangeiro" - há um parentesco etimológico entre as palavras em inglês e francês -, por outro lado é possível questionar, indo mais longe, de que maneira pode-se falar no sentido do "estranho" como algo próximo, quase familiar em sua estranheza.

$\mathrm{Na}$ raiz latina, o "alter" se refere fundamentalmente a um "outro", que também pode ser pensado em termos de um "alien”, "o que está fora" ou "o estrangeiro", já com conotações políticas referentes ao grego "xenos", definição historicamente carregada de sentidos mais negativos, como em "xenofobia". A situação do "fora", no entanto, não se refere 
exclusivamente às fronteiras geográficas, mas parece se instaurar igualmente entre aqueles que pertencem a um mesmo espaço e, em termos ainda mais restritos, ao processo de relação entre alteridade e diferença. $\mathrm{O}$ estranho não é sinônimo de estrangeiro, mas ambos estão dentro da ideia de um deslocamento em relação a algo conhecido.

Este texto examina alguns modos de construção da imagem de uma identidade nacional a partir do estranhamento irônico das próprias práticas, tomando como caso as postagens feitas pela conta BritishLogic, (@BritishLogic), na rede social Twitter. A página, criada em 2013 pela vlogger Hannah Anderson, já postou mais de 4000 mensagens e tem, no momento desta pesquisa, 230 mil seguidores.

Foram considerados todas as postagens da conta British Logic entre dezembro de 2015 e maio de 2016, totalizando 679. Os tweets foram analisados segundo os seguintes aspectos: conteúdo temático, ideia norteadora, relação com a questão do inquietante. Em seguida, procuramos observar as inferências sobre identidade em situações típicas ou pitorescas ligadas ao sentimento de "ser britânico". "Identidade", aqui, é pensada como intersecção entre múltiplas linhas de força, percorrendo desde as práticas culturais, no sentido de Hall (2010), até vínculos políticos relacionados com a noção de "identidade nacional", como a define Smith (2003). Essa intersecção não deixa de ser atravessada por tensionamentos que, em si, aparecem nas postagens como um dos pontos de estranhamento.

Sabemos que redes sociais digitais como o Twitter permitem uma estrutura da conversação online que congrega públicos distintos, atuando a partir de diferentes espaços e temporalidades. Muitas conversações podem ser adensadas e aprofundadas, dando origem a uma reflexão ética sob a forma de um debate online que se intensifica a partir da interconexão entre diferentes contextos comunicativos, os quais reúnem diferentes atores e seus modos de comunicação específicos (MARTINO, MARQUES, 2016). Contudo, nem sempre as conversas que se estabelecem em uma rede social influenciam debates em outros espaços online de interação e debate. Mas é interessante notar como as trocas comunicativas e conversações construídas em plataformas como o Twitter conseguem articular discursos e atores, enquanto eles, a partir da individualidade de suas experiências e relatos, alimentam tais articulações. Por isso, o enfoque analítico das conversações pode ser mais interessante se procurar revelar como os conflitos, dissensos, formas de auto-expressão e expressão coletiva são trabalhados na interação (EVELAND et al., 2011).

Sob esse aspecto, vamos abordar neste artigo menos as dinâmicas de trocas conversacionais moduladas em plataformas interativas de redes sociais online, concentrando- 
nos nos modos como as possibilidades enunciativas e expressivas proporcionadas por redes sociais como Twitter podem promover um processo de reflexão e individuação a partir da organização experiências que possuem como tema o contato com a alteridade e a demarcação de dimensões identitárias (MARQUES, 2016).

Ao mesmo tempo, é importante enfatizar que as redes sociais não podem ser caracterizadas, de partida, como um espaço neutro de expressão subjetiva e coletiva, exatamente por causa de seu caráter corporativista, que envolve estratégias complexas de publicidade, e sua própria concepção empresarial que visa o lucro e é moldada por fatores sociopolíticos, códigos legais e forças de mercado. Contudo, Eveland et al. (2011) afirmam que alguns espaços de interação das redes sociais mobilizam oportunidades de identificação de crenças, valores e enquadramentos a partir dos quais os usuários expõem e negociam sentidos, estabelecendo uma disputa por enquadramentos e, assim, pela inteligibilidade e legitimidade conferida a determinados pontos de vista. Tal constatação nos leva a perceber a importância assumida por uma análise apurada dos contextos enunciativos de trocas on-line diante de questões identitárias (sem nos esquecermos que eles são marcados por desigualdades de acesso e assimetrias de status entre os participantes). Empenhados na produção de enunciados que reiteram vínculos de pertencimento e identificação, os sujeitos em interação online muitas vezes relutam em abrir-se às experiências, narrativas ou contribuições que lhes soam estrangeiras: cada parte percebe a si mesma como auto-suficiente em suas crenças modos de julgar e avaliar condutas, questões e ações.

De modo específico, acreditamos que o Twitter, por sua arquitetura, permite a criação de interconexões entre diferentes contextos comunicativos, reunindo diferentes atores e seus modos de comunicação específicos. Uma análise dos tweets em BritishLogic permite delinear a maneira como a autora da página, britânica, constrói, de maneira irônica, percepções a respeito de sua sociedade a partir de um olhar fundado no estranhamento das práticas cotidianas, às vezes até banais, que, no entanto, se apresentam como indícios de características identitárias mais gerais.

As postagens da conta BritishLogic permitem relacionar as noções de identidade e alteridade - que se constitui no estranhamento das práticas familiares, efetuado, nas postagens, pela seleção de situações cotidianas tornadas relevantes.

As pesquisas sobre o sentido do estranho ocupam um lugar especial dentro das Ciências Sociais, tendo sido objeto de estudos como, para mencionar apenas alguns dos mais conhecidos, os de Elias e Scotson (2014), Jenkins (2008) ou Smith (1991), resvalando, não 
raramente, na fronteira com a psicanálise, como nos trabalhos de Kristeva (1988) ou Koltai (2000; 2015; 2016). É nessa fronteira, com os riscos inerentes à investigação que se arrisca ao interdisciplinar, que se busca trafegar aqui para delinear alguns aspectos da questão levantada.

Nesse sentido, a busca por subsídios em autores da psicanálise, sobretudo em Freud (2010 [1919]), não é feita no sentido de explorar aspectos distantes do local de fala dos autores, mas de procurar pensá-la em sua dimensão de compreensão do mundo social; não se trata de "fazer psicanálise" ou usar indiscriminadamente seus referenciais na busca do que Bocock (1998) identifica como um "Freud sociólogo", mas trabalhar algumas de suas contribuições à compreensão de aspectos do mundo social - pensando, por exemplo, nos caminhos indicados por Guimarães (2011), Hermann (2011), Rouanet (2000), Mezan (1984) ou Dunker (2014).

Retoma-se aqui, também, uma discussão em curso pelos autores no sentido de pesquisar questões relativas à identidade, subjetividade e o estranho (MARQUES, 2009; MARTINO, 2010; MARQUES; MARTINO, 2014; 2015; 2017). O texto está dividido em três partes. Na primeira, discutem-se aspectos da noção de "Inquietante”, proposta por Freud (2010 [1919]), para, a partir daí, buscar-se construir a análise do objeto.

\section{O INQUIETANTE EM SUA RELAÇÃO COM O FAMILIAR}

Foi provavelmente Freud (2010 [1919]), no ensaio intitulado "O inquietante", quem apontou pela primeira vez a relação entre o familiar e o estranho e a maneira como ambos estão diretamente ligados. O estranho não é, necessariamente, aquele ou aquilo que está distante. A proximidade, ao mesmo tempo, não é um sinônimo de familiaridade senão em um nível superficial: as atividades cotidianas, olhadas em sua microscópica complexidade, não deixam de se revestir, quando analisadas, de um estranhamento derivado de sua própria recorrência.

Incluído dentro do que se poderia entender como os estudos "sociais" do criador da Psicanálise (BECOCK, 1998; MEZAN, 1987), o ensaio é uma das incursões de Freud no terreno da Estética - indicação constante, aliás, do primeiro parágrafo do texto. Mas o que significa essa perspectiva?

A obra de arte, em sua forma de representação ao mesmo tempo igual e diferente do elemento representado no que se poderia entender como o modo específico de toda apropriação mimética - a "mimesis", nesse caso, implicando o estranhamento a partir da 
duplicação representacional do objeto - é ao mesmo tempo exemplo e caso-limite da inquietação: a "reprodução" da realidade na representação não deixa de desafiar a percepção do que é, de fato, o "real”, formando uma espécie de deslocamento a partir da qual o estranho se ativa na duplicidade.

No entanto, Freud não prossegue diretamente por essa trilha, optando por dar uma pista a partir do próprio nome: o "inquietante", o "estranho", pode ser abordado em termos comparativos com outras línguas: o Unheimlich alemão, termo de tradução bastante complexa - cf. Souza (2006, 2008) - e ambivalente, indica, entre seus vários sentidos, não apenas a noção de "infamiliar" mas também a possibilidade de se pensar em algo "oculto", "escondido" por conta de uma diferença: no coração do familiar, indica Freud, está o inquietante.

Não se trata, no entanto, de uma diferença proveniente de uma distância relacionada ao espaço de um "fora" geográfico: o "fora" está na perspectiva daquilo que constitui o próprio elemento familiar. Mais do que "estranho", a noção de Unheimlich informa a respeito do "não familiar", com o prefixo "un" dando a forma negativa para o heimlich, "familiar", "conhecido".

O "estranho", no caso, poderia ser pensado sobretudo como o "desfamiliar", o "despróximo" - o uso lexicalmente incorreto, mas menos problemático neste caso, que "distante". O familiar torna-se estranho por conta de uma paradoxal proximidade, e nesse sentido Freud parece indicar que, quanto mais próximo se está de algo, mais isso tende a se mostrar diferente e estranho.

Sua busca, além da questão propriamente linguística, dirige-se para um conjunto de situações nas quais emerge o sentido do inquietante, procurando, a partir daí, isolar o elemento em todas elas. No entanto, Freud (2010 [1919]) logo observa que não existe nada de particularmente especial nas situações que despertam essa sensação, exceto uma proximidade considerável entre o aspecto do sensível - daí, talvez, a escolha pela experiência estética - e o inquietante: o elo entre ambos não reside senão na ausência de um elemento especial sobre o qual poderia recair a análise, mas justamente em sua "normalidade", sua ausência de destaque, o familiar e o ordinário se tornam inquietantes.

O sentido do inquietante, neste caso, é construído por conta da familiaridade nas relações que permite, em um meta-olhar, transformar as relações de proximidade e distância a partir de deslocamentos mínimos, quase imperceptíveis, no índice relacional com a realidade. Freud distingue, aliás, o sentimento do inquietante das noções de terror, espanto e de horror: 
nesses casos, a percepção da causa está, em geral, plenamente visível. Essas sensações tendem a ser provocadas, aliás, pela visibilidade consternadora de algo que não só é completamente estranho como também associam, em si, as possibilidades de reconhecimento de perigo, medo e ameaça.

A sutileza do inquietante decorre igualmente de um deslocamento quase imperceptível da realidade que, ao mesmo tempo, a transforma em algo inesperado mas, de alguma maneira, irreconhecível em sua familiaridade: essa diferença mínima, muitas vezes mais sentida decorrendo daí uma perspectiva estética - do que propriamente analisável do ponto de vista da razão, tende a provocar o efeito de inquietação e estranhamento: é por estar muito próxima, é por ser muito conhecida, quase igual ao que se espera, que a realidade se torna inquietante. O “despróximo" se afigura como o elemento de inquietação.

Esses efeitos de deslocamento ocorrem igualmente no sentido oposto, quando o cotidiano é desnaturalizado de suas práticas e tornado distante de si mesmo, "despróximo" do que poderia ser visto. O cotidiano, em sua duração como elemento de proximidade no qual as ações se desenrolam em um único sentido e um único tom - a monotonia - atravessando a maior parte de suas práticas, pode claramente se distanciar de seus praticantes. O estranhamento em relação ao cotidiano só é possível quando de sua meta-observação como um fenômeno a ser notado.

Mas como notar aquilo que está próximo, o conhecido, o trivial? Não se estaria buscando uma redundância proposital quando se fala de conhecer o que já é conhecido e, portanto, não encerra em si nenhum tipo de informação nova que possa ser somada ao que previamente se sabe?

É neste momento que a inquietação com o cotidiano pode acontecer: quando se transforma essa monótona familiaridade em algo novo, o sentido de estranhamento escondido no familiar tende a vir à tona. Nesse aspecto, a perspectiva de Freud se apresenta para compreender esse fenômeno: tornado distante pela proximidade que o esconde, os elementos do cotidiano se revelam tanto mais fortes quanto menos visíveis são na trama de relações constituída entre eles.

Daí a pergunta sobre o inquietante nas atividades do cotidiano: na monotonia da repetição, não haveria em si a possibilidade de um estranhamento justamente decorrente desse movimento? $\mathrm{Ou}$, colocando na forma de um paradoxo, não seria o inquietante exatamente uma decorrência dessa repetição baseada em um sentido que está além dela, mas do qual não 
se pode saber com precisão - exatamente por se situar em uma esfera diferente da vida, o inconsciente?

\section{AS FIGURAÇÕES DO INQUIETANTE NA DEFINIÇÃO DE SITUAÇÕES INTERACIONAIS}

A argumentação de Freud parece situar o inquietante em uma esfera que permite uma aproximação com questões propostas, em outro sentido, por James (1952 [1890]) e Goffman (1974) em relação à percepção da realidade.

Na medida em que são necessários índices diversos, como indica James (1952), para a definição do que é "real" em relação ao "sonho", chega-se ao ponto do inquietante indicado por Freud: o elemento que parece real, guarda todas as características da realidade, mas, em seus pequenos detalhes, desvia-se para algo diferente.

Na matriz teórica de James (1952), Goffman (1974) observa inúmeros efeitos de estranhamento na esfera da ritualística cotidiana, trazendo questões em um sentido aproximado ao de Freud.

Olhado de perto, o cotidiano torna-se inquietante por conta de sua própria configuração. James, neste aspecto, envolve a noção de realidade em múltiplas direções, sobretudo no sentido de mostrar que "o entendimento de uma situação" - e, novamente, há ecos posteriores em Goffman (1974) - como "real" resulta de esforços da mente para entendêla dessa maneira a partir da exclusão de outras possibilidades. A perspectiva freudiana, no entanto, parece não ceder a essa possibilidade propriamente racional, sobretudo por conta de sua matriz sobre a mente humana.

Enquanto James vê essa aproximação como sendo a marca de distinção entre sonho e realidade, Freud encontra aí um dos caminhos de formação do inquietante. Assim como em alguns sonhos a distinção entre o que é real e o que é sonho se dilui no realismo da experiência vivida durante a noite, também o inquietante reside nas frestas do cotidiano na relação de estranhamento composta pela sua proximidade. Não é o familiar, neste caso, que se torna estranho, mas o olhar que incide sobre ele tende a vê-lo a partir de ângulos e enquadramentos que permitem construir um efeito de estranhamento.

Talvez, neste sentido, seja possível compreender que o inquietante só acontece na presença do familiar. É nas evocações do elemento reprimido diante do familiar que se observa a ocorrência do estranho. Não é gratuitamente que um dos motes privilegiados das 
obras de arte que fazem uso desse recurso seja a transformação de objetos e situações do cotidiano em algo assustador.

A questão proposta por James a respeito da dificuldade de separar a "realidade" de sua percepção volta à tona: como saber quando se está diante de algo real? A resposta, em Freud, não é revestida de nenhuma simplicidade. Longe de uma divisão rígida entre "real" e "irreal", ou, mais ainda, "normal" e "anormal", essa divisão parece ser trabalhada muito mais em termos de um gradiente do que uma separação direta: na medida em que os processos mentais não podem ser mapeados em sua totalidade - o inconsciente nos torna estranhos a nós mesmos - e permanecem, em boa parte, desconhecidos, a definição do que é uma "realidade" não alcança sua totalidade. Não por acaso, o sentido do inquietante emerge, entre outros elementos, dessa zona inexplorada e inexplorável da percepção, na qual, perdida entre espaços indefiníveis, a percepção tende a se tornar nublada.

No sentido de estranhamento do familiar, tornado inquietante quando de sua observação de qualquer ponto de vista que não seja o da velocidade das relações cotidianas, busca-se pensar o objeto deste texto. A inquietação revelada com as próprias práticas do dia a dia, delineada continuamente pelo discurso constante no twitter, não deixa de guardar inúmeras possibilidades de compreensão diante do sentido de estranhamento - mas a partir da incidência de um olhar que provoca esse efeito de estranhamento, como ocorre na conta @BritishLogic.

\subsection{As principais nuances da questão: estranhamentos}

O twitter British Logic foi criado em 2013 pela inglesa Hannah Anderson, administradora da página ativa. Em suas postagens é possível identificar o estranhamento presente nos atos de comunicação mais simples, tornados relevantes exatamente a partir do momento em que são objetivados no momento de uma reflexão. O cotidiano, nesse aspecto, é dotado de um sentido de unidade que se torna exatamente o responsável pela construção de uma inquietação: visto em seu conjunto, o aleatório das ações cotidianas parece ser estranhamente organizado em um quadro de práticas identitárias.

Esse twitter pode ser considerado representativo dessa perspectiva do inquietante no ato comunicacional na medida em que toma como ponto de partida situações cotidianas das mais simples, como esperar em uma fila ou andar de ônibus. No entanto, o olhar de estranhamento sobre essas práticas caminha no sentido não apenas de desnaturalizá-las, mas 
também na criação de um efeito de deslocamento em relação ao familiar no limite de seu reconhecimento.

O olhar encontra o estranhamento também a partir da presença de um componente crítico na medida em que o retrato desvelado ao longo das postagens, narradas com elementos de ironia referente a um contínuo jogo de proximidade e distanciamento em relação a atitudes e comportamentos recorrentes do que representa, na visão da conta, a "britishness".

A estratégia textual usada para isso é um dos primeiros pontos a serem ressaltados. Trata-se de um discurso voltado sobretudo para a descrição, aparentemente "sem julgamentos", de situações cotidianas banais, como ir a um supermercado ou conversar em um bar. No entanto, é a apresentação desses momentos, secundada pela inferência dos sentimentos não verbalizados pela dinâmica da situação, a responsável por despertar a atenção: as postagens lançam luz sobre situações que, de outra maneira, se perderiam no âmbito da velocidade cotidiana, provocando uma reflexão a seu respeito. O trivial, em sua familiaridade, torna-se inquietante.

A descrição das ações cotidianas feitas pela autora é sumária. Não parece existir, nas postagens, nenhum elemento inverossímil: ao contrário, é exatamente a verossimilhança, com largo uso de linguagem denotativa, um dos elementos responsáveis pelo estranhamento. Em sua trivialidade, desvela o inquietante do cotidiano:

Failing to grab someone's attention after saying "excuse me" twice, meaning you must abandon all hope of interaction forever (British Logichttps://twitter.com/BritishLogic@BritishLogicMay 25)².

Muitos tweets ajudam a autora a definir esta ou daquela experiência, ou a testemunhar sobre tal ou tal fato que atravessa as práticas cotidianas, em um delicado jogo de aproximação e afastamento do trivial das situações. Falar acerca das próprias impressões e percepções estabelece uma narrativa afetiva de identidade, na qual o "eu" é estabelecido como protagonista a partir do qual se realizará a apropriação reflexiva da alteridade e do mundo.

O retrato que emerge das postagens da autora pode ser entendido como decorrente de um estranhamento em relação aos elementos que, de acordo com certo senso comum à beira do estereótipo, poderiam ser identificados como "identidade inglesa". Uma imagem, sem dúvida, pré-fabricada, refletindo talvez não apenas expectativas em relação a si mesmos, mas,

\footnotetext{
2 "Não conseguir atrair a atenção de alguém após dizer 'com licença' duas vezes significa que você deve abandonar toda a esperança de interação social para sempre” (Tradução dos autores).
} 
igualmente, uma espécie de “caráter” britânico aí identificável - o que não deixa de ser tematizado:

I'm from England so I'mEnglish, I'm from Britain so I'm British, I'm from the United Kingdom so I'm... THERE IS NO WORD (British Logichttps://twitter.com/BritishLogic@BritishLogicMar 12)3.

Talvez não seja errado, nesse caso, observar o desvelamento do que é identificável como a pretensão de um "ethos" específico a partir das ações cotidianas: se, como indica Aristóteles em sua "Ética à Nicômaco", as práticas definem o caráter, a descrição das atitudes dentro de "British Logic" trabalha no sentido de povoar um imaginário da "britanidade" ("britishness").

A página "British Logic" faz o tempo todo um jogo com o próprio estereótipo, criando, na identificação de situações “típicas”, um efeito de estranhamento em relação a si mesma, inclusive a construção de interditos. A revelação discursiva desses interditos sociais na página British Logic permite compreender essa divisão justamente a partir da supressão das possibilidades de uma fala (acompanhada da descrição da situação, entre asteriscos):

\section{"*someone stands onyour toe* You: "sorry"”, (British} Logichttps://twitter.com/BritishLogic@BritishLogicFeb 2)4.

As postagens de British Logic utilizam um humor irônico como uma das maneiras de criar o estranhamento em relação às práticas cotidianas naturalizadas. Esse uso da linguagem não tem o intuito de reapresentar ou de reterritorializar o cotidiano por meio da indistinção entre as temporalidades e espacialidades do espaço virtual e do espaço do presente (o aqui agora vivenciado). As postagens parecem se servir justamente da distinção entre elas para extrair do cotidiano (de forma sutil ou não) o inquietante, as espessuras e os não-ditos.

Não é porque as postagens tratam de temas ordinários que a experiência se dá de modo tranqüilo e isento de tensões. Toda desterritorialização, todo deslocamento do já conhecido ocorre em meio a turbulências e não configuram uma passagem silenciosa de um espaço a outro, de um tempo a outro. A experiência promovida pelo inquietante é da ordem da suspensão (e por vezes de ruptura) e da produção de nova ancoragem (dos sujeitos, dos objetos, das cenas, dos tempos e espaços). Esse trabalho de mudança dos modos de aparição,

\footnotetext{
3 “Sou da Inglaterra, portantosou 'inglês', sou da Grã-Bretanha, por isso sou 'Britânico', sou do Reino Unido, por isso sou NÃO HÁ COMO DIZER ISSO”. (Tradução dos autores).

4 “Alguém pisa no seu pé. Você: 'desculpe"”. (Tradução dos autores).
} 
das coordenadas do representável e das formas de sua enunciação altera quadros, ritmos e escalas, proporcionando outras formas de apreender o visível, o audível e sua significação.

A "lógica britânica" da página refere-se sobretudo aos momentos de interação comunicacional com a alteridade, traduzida em movimentos de sociabilidade, sempre efetivadas com dificuldade: o "inglês" narrado é mostrado como uma pessoa retraída, disposta a tomar atitudes em seu prejuízo conquanto isso o poupe de qualquer contato social que não seja estritamente necessário.

Qualquer tipo de interação social é apresentado, ao longo das postagens, como um problema em relação ao que pode acontecer: o mundo social, nos "tweets", é uma infinita fonte de estranhamentos, como se a mais trivial das ações fosse revestida de um caráter duplo:

Nothing is more horrific than being unsure about where you're supposed to queue" (British Logichttps://twitter.com/BritishLogic@BritishLogicApr 3) ${ }^{5}$.

Ou nesta postagem:

Top British Fears: 1) Accidently touching a stranger on the bus 2) Asking someone if they're in the queue 3)Paying for a $27 \mathrm{p}$ item with a $£ 20$ " (British Logichttps://twitter.com/BritishLogic@BritishLogicMar 13) ${ }^{6}$.

O efeito de estranhamento cotidiano permite a observação da noção pensada por Freud: tudo, de alguma maneira, parece estar fora de seu lugar original - o contato social, principalmente, é uma fonte inesgotável de postagens, é retirado de seu elemento enquanto interação ritualística, no sentido de Goffman (1974) e são submetidas, cada uma delas, a uma profunda reflexão à beira do desconforto referente a uma contínua timidez (VERTZMAN, 2014):

Accidentally pressing the button a stop early on the bus and getting off three miles from your destination to avoid any commotion $^{7}$ (British Logichttps://twitter.com/BritishLogic@BritishLogic, Mar 5).

Pagar uma conta no supermercado, participar de uma festa de família ou preparar uma xícara de chá são descritos na página de uma maneira simples que realça o estranhamento: a descrição do familiar confere existência em uma dimensão fora do comum às práticas cotidianas. O destaque de situações triviais recorda o quanto essas práticas são resultado de

\footnotetext{
5 "Nada é pior do que não ter certeza sobre qual fila pegar" (Tradução dos autores).

6 "Principais medos britânicos: (1) tocar acidentalmente um estranho no ônibus (2) Perguntar a alguém se ela está na fila (3) Pagar um ítem de 27 centavos com uma nota de vinte libras"

7 “Apertar acidentalmente o botão "parar" do ônibus antes do ponto significa andar três milhas a pé para evitar comoção" (Tradução dos autores).
} 
convenções que não obedecem necessariamente a nenhum tipo de racionalidade prévia, mas encerram, em seu fechamento, um conjunto aberto e complexo de tomadas de decisão colocadas em questão nos tweets.

Revelada como fruto de escolhas, a ritualística cotidiana é vislumbrada em sua dimensão de construção: a descrição das ações evoca sua estranheza em vários dos posts. $\mathrm{O}$ fato de se destacar o normal permite questionar, imediatamente, por que o consideramos "normal":

The heartbreak of finding an empty teacup when you thought there was one gulp to go (British Logichttps://twitter.com/BritishLogic@BritishLogicMay 23) ${ }^{8}$

Isso fica igualmente claro no momento em que as postagens revelam um descompasso entre a ação e o discurso, revelando as verdadeiras motivações ou sentimentos de um ato, como se a superfície prático-discursiva da vida cotidiana não fosse senão um contínuo estado de repressão daquilo que efetivamente se quer ou se pensa:

Repeating "Sorry, thanks, pardon me" as you struggle through a crowd,even though you're not sorry or thankful and don't want to be pardoned (British Logichttps://twitter.com/BritishLogic@BritishLogicMay 25).

A força poética do cotidiano, fonte de produção do inquietante, reside também em sua possibilidade de dar forma ao comum: uma possibilidade e uma experiência de encontro, de fraternidade precária, de empatia, sem se transformar em algo instituído, em instituição.

\section{CONSIDERAÇÕES FINAIS}

A percepção do inquietante, na vida cotidiana, requer o acionamento de recursos temporais diversos para a concretização desse fenômeno. A emergência do elemento da comunicação enquanto irrupção, mas também início de familiarização, com o estranho torna o momento do inquietante um ponto quase necessário na relação com a alteridade. $\mathrm{O}$ inquietante, nesse sentido, está entrelaçado ao familiar, ao ordinário, ao cotidiano, mas raramente tornado visível exceto no esforço de um recurso à contemplação propícia à percepção do estranhamento.

Como vimos, a formação de um mundo comum está intimamente ligada ao engajamento dos sujeitos a um jogo de separações que vinculam e de vínculos que separam,

\footnotetext{
8 “A tristeza de perceber que sua caneca de chá está vazia quando você achava que ainda tinha mais um gole"

9 "Ficar repetindo "Lamento, obrigado, perdão" enquanto você se esgueira em uma multidão, muito embora você não lamente, nem se sinta agradecido nem queira ser perdoado". (Tradução dos autores).
} 
preservando sempre a diferença, a estranheza diante da alteridade. O objetivo do comum não é fazer coincidir semelhantes e desemelhantes, mas revelar que a partilha de vínculos de pertencimento é feita, ao mesmo tempo, da tentativa de estabelecer ligações entre universos dissonantes e da constante fragilidade desses vínculos. O comum é, assim, intervalar, isto é, ele conecta sujeitos e universos particulares de modo a permitir um campo partilhado de trocas e agenciamentos marcado por interrupções, fraturas e intervalos que tornam possível a produção de um novo campo de experiências. Tais experiências desestabilizam posições de identificação e reavivam a dimensão infamiliar que torna possível a consideração do outro, a apreensão sensível de seu mundo e de suas marcas sem necessariamente incorporá-las ao universo do "mesmo".

Operar no intervalo, na pausa (momentos em que o tempo se desdobra outramente) nos permite encontrar a diferença, a peculiaridade e a novidade, e também produzir desidentificações: rupturas com uma ordem discursiva que oferece a cada pessoa seu lugar na ordem das coisas, um lugar atrelado à uma identidade exclusiva (MARQUES; MAFRA, 2014). Nas análises aqui produzidas vimos como a experiência do banal pode ser constantemente posta em causa, proporcionando aos sujeitos pausas à experimentação e à suspeição: desconstruindo-se, o sujeito constrói-se distinto e oferece rupturas à ordem estabelecida.

\section{REFERÊNCIAS}

ANDRÉ, M. Ética das Paixões: uma teoria psicanalítica do afeto. Rio de Janeiro: Zahar, 2001.

BOCOCK, R. Sigmund Freud. Londres: Routledge, 1998.

DUNKER, C. Mal-estar, sintoma, angústia. São Paulo: Boitempo, 2011.

ELIAS, N.; SCOTSMAN, J. Os estabelecidos e os outsiders. Rio de Janeiro: Jorge Zahar, 2010. EVELAND, William; MOREY, Alyssa; HUTCHENS, Myiah. Beyond Deliberation: New Directions for the Study of Informal Political Conversation from a Communication Perspective. Journal of Communication, n. 61, 2011, p. 1082-1103.

FREUD, S. "O inquietante". In: Análise de uma fobia de um menino de cinco anos e outros textos. São Paulo: Companhia das Letras, 2010 [1919].

GOFFMAN, E. Frame analysis. Londres: Penguin, 1974.

GUIMARÃES, V. C. Sujeito e cultura em 'O mal-estar na civilização'. Goiânia : Ed. PUC-GO, 2011. 
HERMANN, N. Breve investigação genealógica sobre o outro. Educação e Sociedade, Campinas, v. 32, n. 114, p. 137-149, jan.-mar. 2011.

JAMES, W. Principles of Psychology. Nova York: Brittannica, 1952.

JENKINS, R. Social Identity. Londres: Routledge, 2008.

KOLTAI, C. Entre psicanálise e história: o testemunho. Psicologia USP, Vol. 27, no. 1, pp. 24-30, 2016.

KOLTAI, C. Política e Psicanálise: o estrangeiro. São Paulo: Escuta, 2000.

KOLTAI, C. Totem e Tabu: um mito freudiano. Rio de Janeiro: Civilização Brasileira, 2015.

KRISTEVA, J. Etranger a nous-memes. Paris: Gallimard, 1988.

MARQUES, A. C. S.; MAFRA, R.L.M. . O diálogo, o acontecimento e a criação de cenas de dissenso em contextos organizacionais. Dispositiva, v. 2, p. 2-20, 2014.

MARQUES, A. C. S.; MARTINO, L. M. S. 'Não fale com estranhos': solidariedade e comunicação entre identidade e alteridade. Famecos, v. 24, no. 1,p. 24930-24940, 2017 a.

MARQUES, A. C. S.; MARTINO, L. M. S. A comunicação, o comum e a alteridade: para umaepistemologia da experiênciaestética. Logos, v. 22, p. 31-44, 2015.

MARQUES, A. C. S.; MARTINO, L. M. S. Mídia, ética e esfera pública. Belo Horizonte: Selo PPGCOM, 2016.

MARQUES, A. Dimensões do processo comunicativo na deliberação online. In: MENDONÇA, R. F.; PEREIRA, M. A.; FILGUEIRAS, F. (orgs.). Democracia digital. Belo Horizonte: Ed. UFMG, 2016, p. 237-262.

MARTINO, L. M. S. Comunicação e Identidade. São Paulo: Paulus, 2010.

MARTINO, L. M. S.; MARQUES, A. C. S. Aproximações e ambivalências epistemológicas da pesquisa que se constitui entre a comunicação e o comunicar. Lumina, v. 18, 2014, p. 1-19.

MEZAN, R. Freud, pensador da cultura. São Paulo: Brasiliense, 1987.

SMITH, A. D. National Identity. Nevada: Nevada University Press, 1991.

SOUZA, M. R. A "fabricação do estranho" em antropologia e psicanálise. Psychê, Ano 10, no 19, set-dez/2006, p. 33-46.

SOUZA, M. R. A psicanálise diante do outro (ou o "inquietante" divã de Procusto). Psychê, vol. 12, n. 23, dezembro, 2008.

SOUZA, P. C. As palavras de Freud. São Paulo: Companhia das Letras, 2010. 


\section{Luis Mauro Sá Martino}

Professor do Programa de Pós-Graduação em Comunicação da Faculdade Cásper Líbero e pesquisador da Faculdade Cásper Líbero, SP. Doutor em Ciências Sociais pela PUC-SP. Foi pesquisador-bolsista na Universidade de East Anglia, na Inglaterra e é autor dos livros Métodos de Pesquisa em Comunicação (Vozes, 2018), Teoria da Comunicação (Vozes, 2009), Comunicação e Identidade (2010) e The Mediatization of Religion, publicado pela editora britânica Routledge em 2016. Publicou, em co-autoria com Ângela Marques, o livro Ética, Mídia e Comunicação (Summus, 2018).

\section{Ângela Cristina Salgueiro Marques}

Professora do Programa de Pós-Graduação em Comunicação da UFMG. Doutora em Comunicação Social pela UFMG. É pesquisadora do CNPq e tem pós-doutorado na Universidade Stendhal, Grenoble III, na França. É autora dos livros Apelos solidários (Intermeios, 2017), escrito com Angie Biondi; Diálogos e Dissidências: M. Foucault e J. Rancière (Appris, 2018), com Marco Aurélio Prado; e Ética, Mídia e Comunicação (Summus, 2018), com Luis Mauro Sá Martino. É organizadora do livro Vulnerabilidades, justiça e resistências nas interações comunicativas (SELO PPGCOM, 2018).

\section{@ $\odot \otimes 0$}

Esta obra está licenciado com uma Licença

Creative Commons Atribuição-NãoComercial-CompartilhaIgual 4.0 Internacional 